\title{
Rancang Bangun Sistem Informasi Bank Sampah di Desa Paguyangan
}

\author{
Lasmedi Afuan*1, Nofiyati ${ }^{2}$, Nasichatul Umayah ${ }^{3}$ \\ ${ }^{1,2,3}$ Program Studi Teknik Informatika, Universitas Jenderal Soedirman \\ email: lasmedi.afuan@unsoed.ac.id*1,nofiyati@unsoed.ac.id ${ }^{2}$, ichaumayah37@gmail.com ${ }^{3}$
}

(Received: 11 Februari 2021/ Accepted: 12 Maret 2021 / Published Online: 20 Juni 2021)

\begin{abstract}
Abstrak
Sampah merupakan bahan sisa hasil suatu proses produksi, baik industri maupun rumah tangga. Berdasarkan data statistika kabupaten Brebes, kecamatan Paguyangan menduduki urutan ke-4 dengan rata-rata sampah perhari adalah $249,62 \mathrm{~m}^{3}$. Paguyangan yang nerupakan salah satu desa di kecamatan Paguyangan. Paguyangan memiliki permasalahan sampah dimana masyarakat masih memiliki kebiasaan membuang sampah di sungai dan pekarangan sekitar rumah. Berdasarkan hal tersebut Balai Desa Paguyangan berencana membangun bank sampah untuk mengatasi permasalahan tersebut. Untuk memudahkan manajemen dalam pengelolaan pada Bank Sampah seperti pencatatan transaksi tabungan maka penelitian ini melakukan rancang bangun Sistem Informasi Bank Sampah (SIBS) berbasis web. SIBS merupakan sistem informasi yang digunakan untuk membantu proses transaksi sampah pada bank sampah. Tujuan dari SIBS ini adalah untuk memudahkan petugas dan nasabah dalam memproses pelayanan di bank sampah. Metodologi yang digunakan dalam pengembangan sistem adalah metode Waterfall. Pengembangan SIBS menggunakan PHP sebagai bahasa pemrograman dan MySql sebagai Database Management System. Hasil dari penelitian ini adalah sebuah sistem informasi yang dapat digunakan dalam pengelolaan transaksi pengelolaan sampah. Hasil pengujian sistem menggunakan Blackbox Testing dan Mean Opinion Score (MOS) memperoleh semua komponen pada sistem ini berjalan dengan baik seuai dengan kebutuhan.
\end{abstract}

Kata kunci: Bank Sampah, Sampah, Sistem Informasi, Waterfall

\begin{abstract}
Garbage is the residual material resulting from a production process, both industry and households. Based on Brebes district's statistical data, the Paguyangan sub-district is in fourth place with an average of $249.62 \mathrm{~m} 3$ of garbage per day. Paguyangan is one of the villages in the Paguyangan subdistrict. Paguyangan has a garbage problem where people still have the habit of throwing garbage in the river and yards around the house. Based on this, the Paguyangan Village Hall plans to build a garbage bank to overcome the problem. A garbage bank managed activities such as recording saving's transactions. This study conducted a web-based design of the Garbage Bank Information System (SIBS). SIBS is an information system used to help process garbage transactions at a garbage bank. The purpose of this SIBS is to facilitate officers and customers in processing services at the garbage bank. The methodology used in system development is the Waterfall method. SIBS development uses PHP as a programming language and MySql as the DBMS. The result of this research is an information system that can be used in the management of Waste Management transactions. The results of system testing using Black box Testing and Mean Opinion Score (MOS) obtained that all components in this system are running well according to needs.
\end{abstract}

Keywords: Information Systems, Garbage, Garbage Bank, Waterfall.

\section{PENDAHULUAN}

Perkembangan teknologi informasi maju dengan begitu pesatnya (Tiawan \& Afuan, 2020). Teknologi informasi telah dimanfaatkan diberbagai bidang kehidupan manusia. Pemanfaatan TIK antara lain: bidang pemerintahaan, pertahanan dan keamanan, 
kesehatan,lingkungan, dan pendidikan. Teknologi informasi telah menjadi bagian yang sangat penting dalam organisasi, TIK telah mendukung operasional kegiatan dalam organisasi (Tiawan \& Afuan, 2020). Untuk mendukung dan mempermudah aktivitas manusia, berbagai sistem informasi telah dikembangkan diantaranya sistem informasi pengelolaan persediaan barang (Budiman \& Mulyani, 2017), sistem informasi kerjasama (Welda \& Minartiningtyas, 2017), sistem informasi pengelolaan tugas akhir (Mustianti \& Albar, 2020), sistem informasi penyewaan mobil (Septavia, Gunadhi, \& Kurniawati, 2016), aplikasi pengeloaan projek (Tiawan \& Afuan, 2020), aplikasi MarketPlace (Fauzi, Wibowo, \& Putri, 2018), layanan jasa (Joanda, Priyandari, \& Zakaria, 2014), sistem informasi pelayanan perkantoran terpadu (Ariyadi \& Bahar, 2016), aplikasi sentimen analisis (Afuan, 2018), sistem informasi pelayanan jasa laundry (Kamil \& Duhani, 2016), sistem informasi data klien (Muntohar, 2020), pemasaran kopi (Yulistina \& Arianti, 2019) dan masih banyak lagi sistem informasi yang dikembangkan untuk membantu aktivitas manusia.

Istilah sampah sudah tidak asing lagi di telinga masyarakat. Jika mendengar istilah sampah, tentunya dalam pikiran beberapa orang adalah setumpuk limbah yang menimbulkan aroma busuk yang sangat menyengat. Di Indonesia masalah sampah sudah menjadi sorotan publik. Jumlah sampah terus meningkat di setiap tahunnya. Tahun 2019, tercatat produksi sampah di Indonesia 66-67 juta ton sampah (Permana, 2019). Jumlah tersebut lebih tinggi dari jumlah rata-rata sampah per tahun yaitu 64 ton. Sampah merupakan musuh bagi lingkungan, sampah juga menjadi masalah di hampir setiap kota di Indonesia bahkan menjadi masalah yang serius yang dihadapi oleh desa, yaitu bagaimana mengolah sampah itu sendiri. Penanganan sampah yang dapat dilakukan adalah dengan dibuatkan bank sampah. Bank sampah merupakan strategi untuk membangun kepedulian masyarakat dengan cara pengumpulan dan pemilahan sampah. Bank sampah ini menggunakan metode 3R (reducereuse- recycle) karena sampah menjadi sumber daya di industri melalui proses daur ulang.

Data statistika kabupaten Brebes, kecamatan Paguyangan menduduki urutan ke-4 dengan rata-rata sampah perhari adalah 249,62 $\mathrm{m}^{\mathbf{3}}$ (Statistik, 2020).Desa Paguyangan yang nerupakan salah satu desa pada kecamatan Paguyangan memiliki permasalahan sampah dimana masyarakat masih memiliki kebiasaan membuang sampah di sungai dan di pekarangan sekitar rumah. Keadaan ini terjadi karena belum adanya tempat pembuangan sampah dan tong sampah di depan rumah warga desa Paguyangan. Berdasarkan hal tersebut Balai Desa Paguyangan membuat rencana akan membangun bank sampah untuk mengatasi permasalahan sampah.

Agar memudahkan manajemen dalam pengelolaan pada Bank Sampah seperti pencatatan transaksi tabungan maka penelitian ini telah melakukan rancang bangun Sistem Informasi Bank Sampah (SIBS) berbasis web. Penelitian sejenis mengenai SIBS sudah dilakukan oleh beberapa peneliti diantaranya Lidimilah \& Hermanto (2018) mengembangkan Sistem informasi bank sampah menggunakan Visual Basic 2010 dan menggunakan MySq1 sebagai Database Management System (DBMS), hanya saja sistem yang dikembangkan belum mendukung Client-Server. Penelitian (Juliany, Salamuddin, \& Dewi, 2018) dan (Samudi, Brawijaya, \& Widodo, 2018) juga mengembangkan SIBS, penelitian yang dilakukan mengembangkan SIBS berbasis web, pada penelitian tersebut sudah menerapkan konsep Client-Server, mencatat transaksi nasabah seperti cek saldo dan menabung. SIBS berbasis web merupakan sistem informasi yang digunakan untuk membantu proses transaksi sampah pada bank sampah. Tujuan dari SIBS ini adalah untuk memudahkan petugas dan nasabah dalam memproses pelayanan di bank sampah secara efisien dan efektif. Selain itu mempermudah nasabah mengecek saldo. 


\section{METODE}

Ada beberapa tahapan yang dilakukan untuk menyelesaikan permasalahan penelitian antara lain pengumpulan data, analisis dan perancangan, tahapan pengembangan sistem informasi, dan pengujian sistem informasi. Pada tahapan pengumpulan data dilakukan dengan menggunakan metode wawancara dan observasi. Untuk wawancara dilakukan kepada narasumber, dengan tujuan untuk memproleh gambaran mengenai kebutuhan dan alur dalam pengelolaan pada bank sampah. Sedangkan observasi dilakukan dengan mengamati data apa saja yang akan digunakan dalam kegiatan pengelolaan bank sampah.

Pada tahapan perancangan SIBS, metode pengembangan yang digunakan adalah metode waterfall (Presman, 2012). Metode waterfall merupakan hal yang menggambarkan pendekatan secara sistematis dan juga berurutan (step by step) dimana kemajuan atau perkembangan seperti air terjun yang mengalir ke bawah pada sebuah pengembangan perangkat lunak. Tahapan dengan spesifikasi kebutuhan pengguna (requirement analisis), system design, implementation, integration and testing, serta maintenance (Presman, 2012). Pada tahapan perancangan sistem akan mengahasilkan perancangan untuk basis data menggunakan Entity Relationship Diagram (ERD) dan Data Flow Diagram (DFD) menggambarkan kerangka sistem yang nantinya akan dibangun sehingga mempermudah untuk proses pembuatan sistem yang dibutuhkan oleh pengguna.

Untuk tahapan pengembangan dilakukan dengan mengimplementasikan hasil perancangan yang dilakukan. Proses pengembangan SIBS menggunakan PHP sebagai bahasa pemrogramannya dan MySql sebagai Database Management System (DBMS). Tahapan selanjutanya dari penelitian ini adalah pengujian sistem informasi. Pengujian menggunakan metode BlackBox Testing (Jaya, 2018; Kusrini, Fathurrahmani, \& Sayyidati, 2020; Suprapto, Fauziah, Fitri, \& Hayati, 2020). Pengujian ini dilakukan untuk mengetahui kekurangan dan kesalahan apa saja yang ada dalam sistem. Sistem akan diuji dengan melakukan percobaan secara langsung oleh pengguna. Pengujian yang akan dilakukan adalah menggunakan pengujian black-box dan Mean Opinion Score(Silva, Galvão, Mota, \& Iano, 2015). Pengujian black-box merupakan proses pengujian dengan cara mengecek satu - persatu fungsi yang telah dibuat, apakah sudah dibuat sesuai dengan user requirement. Pengujian Mean Opinion Score (MOS) ini dilakukan dengan melibatkan beberapa responden untuk mencoba menggunakan SIBS.

\section{HASIL DAN PEMBAHASAN \\ Hasil}

Hasil dari penelitian ini adalah sebuah sistem informasi pengelolaan bank sampah di desa Paguyangan. Sistem ini dapat digunakan untuk mempermudah dalam pengelolaan transaksi pada bank sampah di desa Paguyangan. Dalam pengembangan sistem, tahapan awal setelah dilakukan pengumpulan data adalah tahap analisis. Tahap ini dilakukan untuk mengidentifikasi permasalahan dan kebutuhan terkait sistem informasi yang akan di kembangkan. Tahap analisis ini dilakukan dengan cara melakukan wawancara dan observasi untuk menyusun user requirement. Wawancara dilakukan kepada narasumber, yaitu Bapak Saefudin Selaku sekretaris Balai Desa Paguyangan. SIBS akan digunakan oleh 3 jenis pengguna, yaitu:

1. Admin

Merupakan jenis pengguna yang memiliki kedudukan paling tinggi di dalam sistem dan dapat meninjau seluruh sistem aspek, mulai dari pengelolaan user, pengelolaan pengajuan surat, serta dapat membuat laporan surat.

2. Manajer

Merupakan jenis pengguna yang memiliki hak akses untuk dapat melihat data pengelolaan sampah. 
3. Nasabah

Merupakan jenis pengguna berasal dari masyarakat yang dapat menabung di bank sampah.

Dari identifikasi peran pengguna yang sudah dijabarkan dapat diidentifikasi kebutuhan masing - masing pengguna seperti tabel 1 .

Tabel 1. Identifikasi Kebutuhan Pengguna

\begin{tabular}{cll}
\hline User & \multicolumn{1}{c}{ Kebutuhan User } & \multicolumn{1}{c}{ Kode URS } \\
\hline Nasabah & Melakukan Login dengan username dan password & URS-SIBS-1 \\
& Membuat akun & URS-SIBS-2 \\
& Dapat melihat data tarik tunai & URS-SIBS-3 \\
& Dapat melihat data transaksi & URS-SIBS-4 \\
Admin & Melakukan Login dengan username dan password & URS-SIBS-5 \\
& Dapat mengelola User & URS-SIBS-6 \\
& Dapat mengelola transaksi & URS-SIBS-7 \\
& Dapat mengelola data sampah & URS-SIBS-8 \\
& Dapat mengelola data setor pengepul & URS-SIBS-9 \\
& Dapat Mencetak Laporan & URS-SIBS-10 \\
Manajer & Melakukan Login dengan username dan password & URS-SIBS-11 \\
& Dapat melihat data transaksi & URS-SIBS-12 \\
& Dapat melihat data setor pengepul & URS-SIBS-13 \\
& Dapat melihat data tarik tunai & URS-SIBS-14 \\
\hline
\end{tabular}

Tahap perancangan merupakan tahap kedua yang dilakukan ketika tahap analisis sudah selesai dilakukan. Tahap perancangan pada SIBS digunakan beberapa diagram dan tabel yang digunakan untuk menjelaskan aplikasi yang akan dibuat yaitu DFD, ERD, dan perancangan Tabel. DFD merupakan alat yang biasa dipakai untuk menggambarkan proses, fungsi, dan jalannya data atau informasi dalam sistem. Data Flow Diagram dalam penelitian ini terdiri dari 3 level yaitu DFD Level 0, DFD Level 1, dan DFDLevel 2. DFL Level 0 ditampilkan pada gambar 1 .

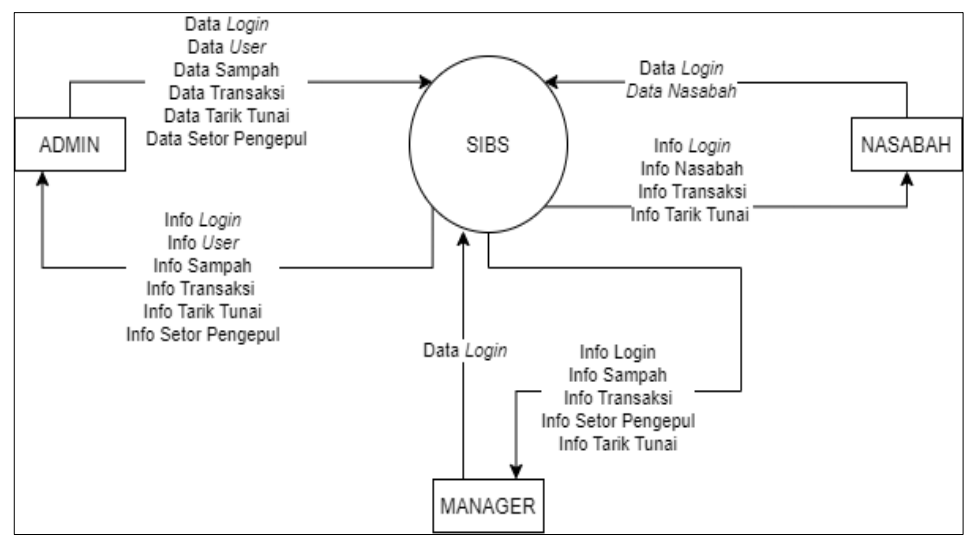

Gambar 1. DFD level 0

DFD level 0 menggambarkan garis besar jalannya data atau informasi secara keseluruhan kepada user terkait seperti Admin, Manajer dan Nasabah. Selanjutnya adalah penjabaran detail dari DFD Level 0 menjadi DFD Level 1, Gambar 2 menampilkan gambaran dari DFD Level 2. 


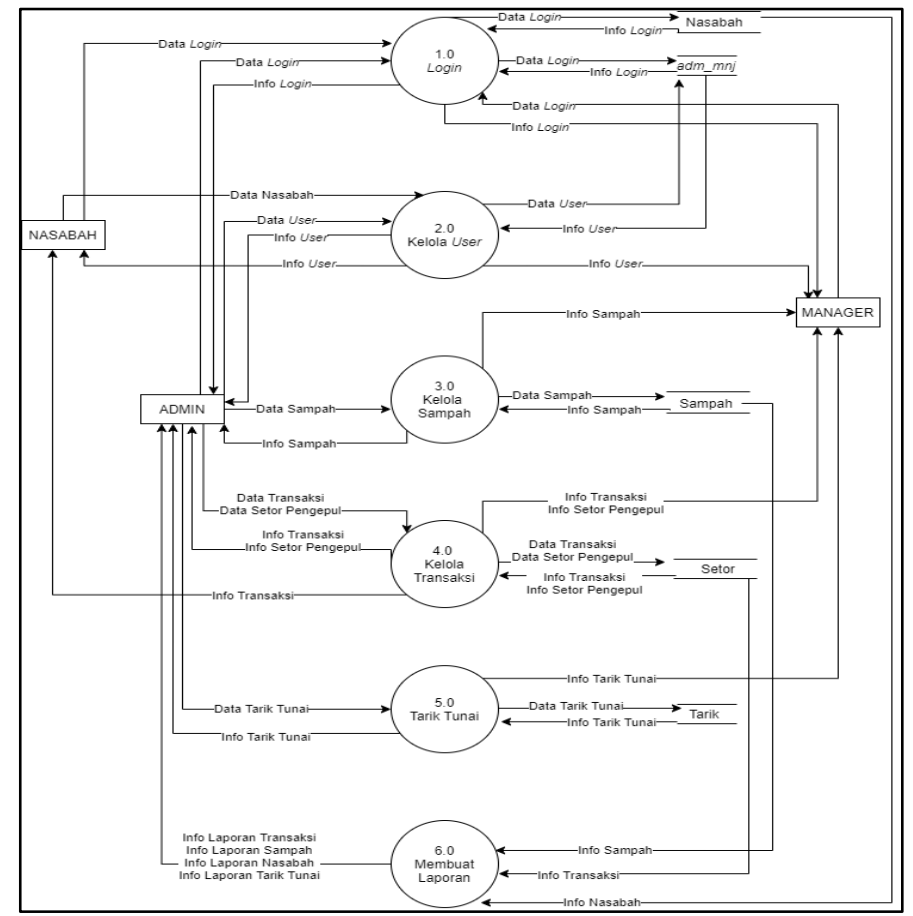

Gambar 2. DFD level 1

DFD Level 1 merupakan penjabaran dari DFD Level 0 (Diagram Konteks). Dalam DFD Level 1 ini dijelaskan secara rinci dari kerja sistem dengan membagi sistem menjadi beberapa proses yang saling berkaitan. Langkah berikutnya dalam peracangan adalah merancang Entity Relationship Diagram (ERD). ERD merupakan diagram yang menjelaskan hubungan antara entitas yang ada pada sistem ini. ERD pada SIBS akan di jelaskan pada gambar 3.

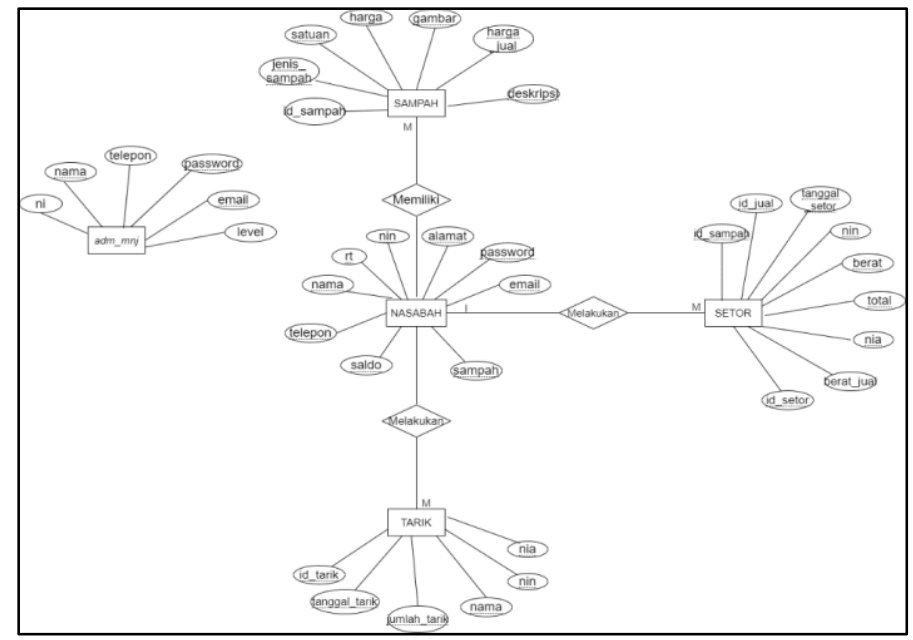

Gambar 3. ERD

Terdapat 5 entitas yang saling berhubungan yaitu user, nasabah, setor, sampah dan tarik. Dari ERD, selanjutnya dilakukan perancangan tabel. Perancangan tabel yang ada pada basis data yang digunakan pada SIBS yaitu tabel user, tabel nasabah, tabel sampah, tabel setor, tabel tarik. Tabel user dapat ditunjukkan pada tabel 2, 3, dan 4. 
Tabel 2. Tabel adm_mnj

\begin{tabular}{ccc}
\hline Nama & Tipe & Key \\
\hline Id_user & Int (11) & Primary \\
Nama & Varchar (50) & - \\
Telepon & Varchar (16) & - \\
Email & Varchar (50) & - \\
Level & Enum('admin', 'manajer') & - \\
Password & Varchar (50) & - \\
\hline
\end{tabular}

Tabel 3. Tabel Tarik

\begin{tabular}{ccc}
\hline Nama & Tipe & Key \\
\hline Id_tarik & Int $(10)$ & Primary \\
Tanggal-tarik & Date & - \\
Nin & Varchar(10) & - \\
Nominal & Varchar $(20)$ & - \\
\hline
\end{tabular}

Tabel 2. Tabel Setor

\begin{tabular}{ccc}
\hline Nama & Tipe & Key \\
\hline Id_setor & Int $(11)$ & Primary \\
Id-sampah & Varchar (25) & - \\
Id_jual & Varchar (25) & - \\
berat & Varchar (10) & - \\
Tanggal-setor & Date & \\
Nin & Varchar(50) & - \\
Total & Varchar (50) & - \\
Nia & Varchar (10) & - \\
Berat-jual & $\operatorname{Int}(11)$ & - \\
\hline
\end{tabular}

Tahapan selanjutnya setelah perancangan adalah pengembangan SIBS. Dari tahapan ini menghasilkan beberapa halaman yang dapat digunakan dalam pengelolaan bank sampah. Halaman awal dari SIBS ini adalah halaman login. Halaman Login merupakan halaman pertama kali ditampilkan kepada admin, manajer dan nasabah. Pengguna diwajibkan memasukkan nama pengguna dan sandi yang benar agar bisa masuk ke SIBS. Tampilan dari Halaman Login ditunjukkan pada gambar 4. Jika nama pengguna dan sandi yang masukkan benar, maka pengguna akan masuk ke halaman beranda. Halaman beranda disesuakan dengan jenis akun yaitu nasabah, admin, dan manager.

Halaman Beranda Nasabah merupakan halaman pertama yang akan muncul pada tampilan nasabah yang sudah melakukan login ke dalam sistem ini. Halaman beranda dalam nasabah ini berisi tentang informasi data sampah, data transaksi yang telah dilakukan oleh nasabah. Tampilan Halaman Beranda nasabah dapat ditunjukkan oleh gambar 5. Sementara itu, halaman Beranda Admin merupakan halaman pertama yang akan muncul pada sistem ketika admin sudah melakukan login ke dalam sistem. Halaman Beranda Admin ini berisi tentang informasi terkait pengelolaan sampah pada sistem ini. Tampilan halaman beranda Admin ditunjukkan pada gambar 6. Selanjutnya, halaman manajer merupakan halaman yang pertama yang akan muncul pada tampilan manajer yang sudah melakukan login ke dalam sistem ini. Pada halaman ini menampilkan data-data mengenai hasil pengelolaan sampah. Tampilan halaman manajer ditunjukkan pada gambar 7. 


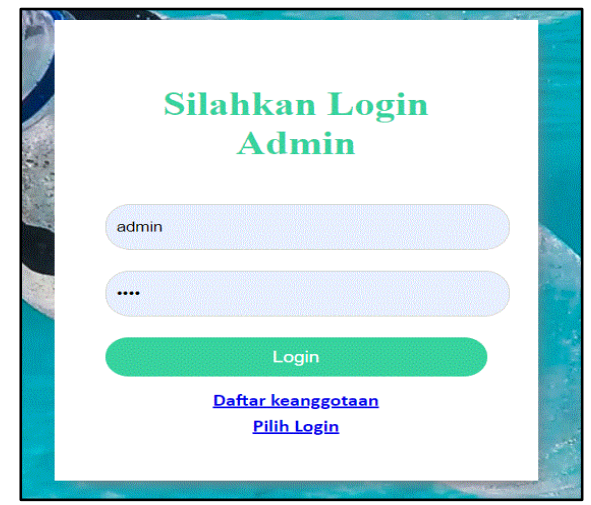

Gambar 4. Halaman Login

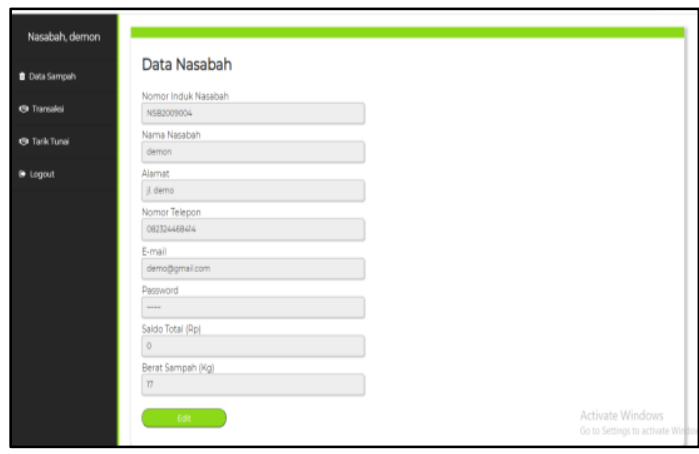

Gambar 5. Halaman Nasabah

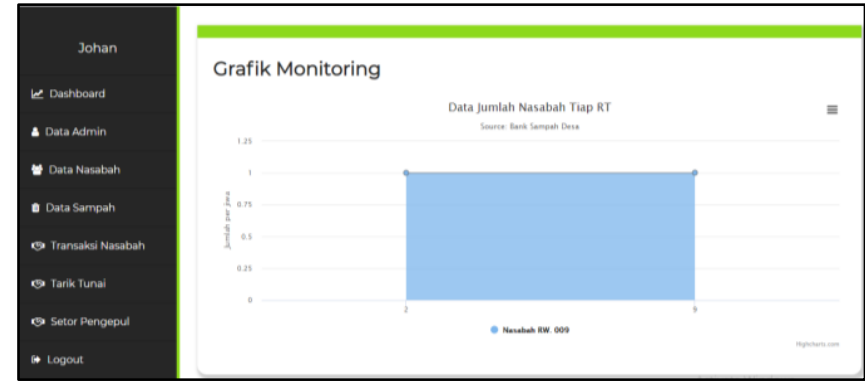

Gambar 6. Halaman Admin

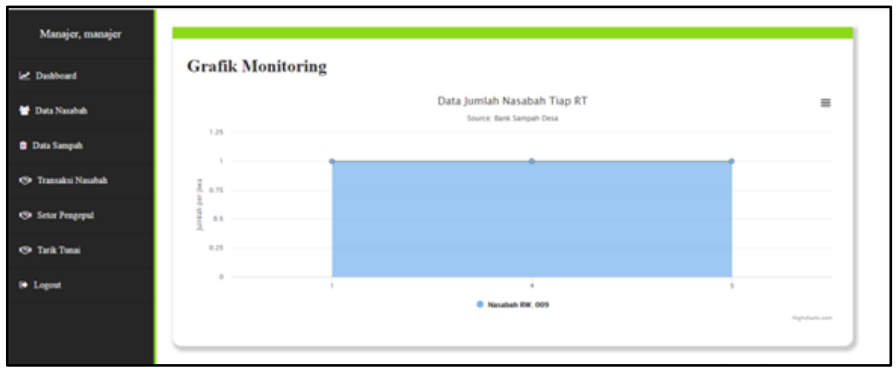

Gambar 7. Halaman Manajer

SIBS yang telah dikembangkan, selanjutnya diuji dengan menggunakan Blackbox testing untuk melihat fungsionalitas sistem dan penggunaan Mean Opinion Score (MOS) untuk melihat pendapat pengguna dalam penggunaan sistem yang telah dikembangkan. Tahap Pengujian sistem ini dilakukan dengan menggunakan metode BlackBox Testing. Blackbox Testing merupakan suatu model atau metode pengujian perangkat lunak yang difokuskan pada fungsionalitas dari perangkat lunak yang diuji. SIBS sudah dilakukan pengujian pada fungsi operasionalnya. Adapun rencana pengujiannya diuraikan pada tabel 5 . 
Tahap pengujian selanjutnya, menggunakan uji MOS (Mean Opinion Score). MOS merupakan metode dalam mengukur kinerja dan kualitas dari sistem yang dibangun. Pengujian ini dilakukan dengan melibatkan beberapa responden untuk mencoba menggunakan sistem, kemudian meminta untuk memberikan penilaian dengan rentang 1 sampai dengan 4. Dimana nilai 1 menyatakan nilai terburuk dan nilai 4 menyatakan nilai terbaik. Kemudian dihitung rata-rata penilaian dari seluruh responden sehingga diperoleh nilai Mean Opinion Score dari sistem tersebut. Untuk pengujian MOS yang dilakukan berbasis user acceptance test (UAT). UAT ini dilakukan oleh 5 responden dengan 10 pertanyaan terkait sistem yang dibangun penulis dengan memberikan bobot penilaian tersebut dapat dilihat pada tabel 6 .

Tabel 5. Pengujian Blackbox

\begin{tabular}{cc}
\hline Kode URS & Kebutuhan \\
\hline URS-SIBS-01 & Dapat login dengan menggunakan username dan password \\
URS-SIBS-02 & Dapat melihat halaman beranda \\
URS-SIBS-03 & Dapat bergabung menjadi nasabah \\
URS-SIBS-04 & Dapat melihat data user \\
URS-SIBS-05 & Dapat mengubah data user \\
URS-SIBS-06 & Dapat menghapus data user \\
URS-SIBS-07 & Dapat menambah data user \\
URS-SIBS-08 & Dapat melihat data sampah \\
URS-SIBS-09 & Dapat menambah data sampah \\
URS-SIBS-10 & Dapat menghapus data sampah \\
URS-SIBS-11 & Dapat memasukkan data tabungan sampah nasabah \\
URS-SIBS-12 & Dapat mengajukkan tarik tunai \\
URS-SIBS-13 & Dapat melihat data pembelian sampah \\
URS-SIBS-14 & Dapat melihat data penjualan sampah ke pengepul \\
URS-SIBS-15 & Dapat memasukkan data penjualan sampah ke pengepul \\
URS-SIBS-16 & Dapat melihat keuntungan bank sampah \\
URS-SIBS-17 & Dapat melihat saldo nasabah \\
URS-SIBS-18 & Dapat melakukan tarik tunai \\
URS-SIBS-19 & Dapat mencetak laporan \\
URS-SIBS-20 & Dapat logout dari sistem \\
\hline
\end{tabular}

Tabel 6. Tabel Hasil Survei Pengujian Sistem

\begin{tabular}{|c|c|c|c|c|}
\hline No & Pertanyaan & SS & $\mathbf{S}$ & KS TS \\
\hline 1. & Sistem SIBS mudah dioperasikan & 4 & 1 & \\
\hline 2. & Tampilan dari SIBS mudah digunakan dan dipahami & 3 & 2 & \\
\hline 3. & Tampilan (user interface) dari sistem SIBS interaktif & 2 & 3 & \\
\hline 4. & Sistem SIBS sangat membantu masyarakat & 4 & 1 & \\
\hline 5. & $\begin{array}{l}\text { Respon waktu mengakses fitur tiap sistem berlangsung cepat } \\
\text { dan stabil }\end{array}$ & 1 & 2 & 2 \\
\hline 6. & Sistem SIBS menampilkan data yang sesuai & 1 & 4 & \\
\hline 7. & SIBS menghasilkan informasi yang terbaru dengan tepat waktu & 3 & 2 & \\
\hline 8. & Fitur pada sistem SIPAK sudah lengkap & & 2 & 3 \\
\hline 9. & $\begin{array}{c}\text { Tidak pernah mengalami error/gangguan saat menjalankan } \\
\text { sistem }\end{array}$ & 2 & 2 & 1 \\
\hline 10. & Informasi pada SIBS mudah dipahami & 3 & 2 & \\
\hline
\end{tabular}


Hasil analisis pengujian yang dilakukan dengan sistem berbasis User Acceptance Test (UAT) maka nilai MO diperoleh ke dalam presentase sebagai berikut:

1. $95 \%$ responden menyatakan sistem SIBS mudah dioperasikan

2. $90 \%$ responden menyatakan tampilan dari SIBS mudah digunakan dan dipahami

3. $85 \%$ responden menyatakan tampilan (user interface) dari sistem SIBS interaktif

4. $95 \%$ responden menyatakan Sistem SIBS sangat membantu masyarakat

5. $70 \%$ responden menyatakan Respon waktu mengakses fitur tiap sistem berlangsung cepat dan stabil

\section{Pembahasan}

Proses pengolahan data yang sebelumnya dilakukan secara manual kini sudah dirancang dan dikembangkan menjadi suatu aplikasi sistem yang sudah terkomputerisasi. Pada Gambar 2 dapat dilihat bahwa SIBS dikembangkan dan dirancang dengan 3 level pengguna yaitu Nasabah, Admin, dan Manager. Identifikasi dari kebutuhan pengguna pada SIBS dapat dilihat pada Tabel 1. Rancangan masukkan, proses dan keluaran pada SIBS bisa dilihat pada Gambar 1. Pada SIBS, pengguna nasabah, admin, dan manager berinteraksi melalui proses 1.0 sampai dengan proses 6.0 seperti yang ditampilkan pada Gambar 1.Untuk menjalankan SIBS, pengguna harus memiliki koneksi internet dan web browser. SIBS dirancang berbasis web agar semua orang dapat mengaksesnya. SIBS juga dilengkapi fitur login untuk menjaga keamanan data-data yang ada. Jika dibandingkan dengan penelitian (Lidimilah \& Hermanto, 2018), (Samudi et al., 2018), dan (Juliany et al., 2018), penelitian ini memiliki beberapa fitur yang lebih baik yaitu selain fitur mengelola transaksi nasabah seperti cek saldo, menabung sampah, terdapat juga fitur pembelian, menampilkan hasil kerajinan, dan fitur notifikasi WhatsApp petugas untuk menjemput sampah. Dari hasil pengujian yang telah dilakukan menggunakan BlackBox Testing dan MOS seperti ditampilkan pada tabel 5 , maka diperoleh hasil bahwa SIBS dapat dioperasikan dengan mudah oleh pengguna, mudah digunakan dan memiliki antar muka yang interaktif.

\section{SIMPULAN}

Penelitian ini telah berhasil mengembangkan Sistem Informasi Bank Sampah (SIBS) di desa Paguyangan. Dari hasil penelitian diambil kesimpulan antara lain dengan adanya SIBS akan lebih memudahkan pengelola dalam pengelolaan sampah. 95 responden menyatakan bahwa SIBS dapat dioperasikan dengan mudah. Dengan adanya sistem bank sampah, sampah akan memiliki nilai ekonomi sehingga masyarakat memperoleh pemasukan selain dari mata pencarian masyarakat yaitu uang yang diperoleh dari penjualan sampah. Sistem bank sampah akan menjadi pendukung dalam menanggulangi permasalahan sampah yang ada di Desa Paguyangan.

\section{REFERENSI}

Afuan, L. (2018). Sentimen Analisis Di Twitter ( Studi Kasus : Resepsi Pernikahan Putri Presiden Ri Ke-7 ). Seminar Nasional Teknologi Informasi Dan Multimedia, 6(1), 1-6.

Ariyadi, B. M., \& Bahar. (2016). Model Aplikasi Sistem Pelayanan Terpadu Pada Kantor Kelurahan. Teknik Informatika, 5(1), 877-1021.

Budiman, A., \& Mulyani, A. (2017). Rancang Bangun Aplikasi Sistem Informasi Persedian Barang di TB. Indah Jaya Berbasis Desktop. Jurnal Algoritma, 13(2), 374-378. https://doi.org/10.33364/algoritma/v.13-2.374

Fauzi, R., Wibowo, S., \& Putri, D. Y. (2018). Perancangan Aplikasi Marketplace Jasa Percetakan Berbasis Website. Fountain of Informatics Journal, 3(1), 5. https://doi.org/10.21111/fij.v3i1.1824 
Jaya, T. S. (2018). Pengujian Aplikasi dengan Metode Blackbox Testing Boundary Value Analysis (Studi Kasus: Kantor Digital Politeknik Negeri Lampung). Jurnal Pengembangan IT (JPIT, 03(02), 45-48.

Joanda, A. D., Priyandari, Y., \& Zakaria, R. (2014). Perancangan Sistem Informasi Manajemen Layanan Jasa Teknologi dan Kerjasama di Lembaga DEF. Jurnal Sistem Informasi, 10(2), 94-107.

Juliany, I. K., Salamuddin, M., \& Dewi, Y. K. (2018). Perancangan Sistem Informasi EMarketplace Bank Sampah Berbasis Web. Semnasteknomedia Online, 6(1), 19-24.

Kamil, H., \& Duhani, A. (2016). Pembangunan Sistem Informasi Pelayanan Jasa Laundry Berbasis Web Dengan Fitur Mobile Pada 21 Laundry Padang. Seminar Nasional Sains Dan Teknologi, 1-9. Jakarta: Fakultas Teknik Universitas Muhammadiyah Jakarta.

Kusrini, W., Fathurrahmani, F., \& Sayyidati, R. (2020). Sistem Pakar untuk Diagnosa Penyakit Ayam Pedaging. Edumatic: Jurnal Pendidikan Informatika, 4(2), 75-84.

Lidimilah, L. F., \& Hermanto. (2018). Sistem informasi Bank Sampah Sukorejo berbasis client server. Jurnal Ilmiah Informatika, 3(1), 193-198.

Muntohar, A. (2020). Sistem Informasi Data Klien Berbasis Java Pada Kantor Notaris dan PPAT Arif. Edumatic: Jurnal Pendidikan Informatika, 4(2), 58-67. https://doi.org/10.29408/edumatic.v4i2.2515

Mustianti, I. B. K. W., \& Albar, M. A. (2020). Sistem Informasi Tugas Akhir Program Studi Teknik Informatika. JTIKA, 2(1), 19-29.

Presman, R. S. (2012). Rekayasa Perangkat Lunak Pendekatan Praktisi Edisi 7 (Buku Satu). Yogjakarta: Andi.

Samudi, Brawijaya, H., \& Widodo, S. (2018). Penerapan Model Waterfall Dalam Sistem Informasi Bank Sampah Berbasis Web. Jurnal Ilmu Pengetahuan Dan Komputer, 3(2), $245-250$.

Septavia, I., Gunadhi, E., \& Kurniawati, R. (2016). Sistem Informasi Penyewaan Mobil Berbasis Web di Jasa Karunia Tour And Travel. Jurnal Algoritma, 12(2), 534-540. https://doi.org/10.33364/algoritma/v.12-2.534

Silva, E., Galvão, L., Mota, E., \& Iano, Y. (2015). Mean Opinion Score measures based on EModel during a VoIP call A Single Comparison On-line and Off-line. The Eleventh Advanced International Conference on Telecommunications OHDQ, 132-135. https://doi.org/10.13140/RG.2.1.1394.9281

Statistik, B. P. (2020). Rata-rata Volume Sampah/Hari Menurut Kecamatan di Kabupaten Brebes.

Suprapto, D. D. A., Fauziah, F., Fitri, I., \& Hayati, N. (2020). Pengembangan Aplikasi Sistem Informasi Smart Register Online Berbasis Android Menggunakan Algoritma BruteForce. Edumatic: Jurnal Pendidikan Informatika, 4(1), 47-56.

Tiawan, I. A., \& Afuan, L. (2020). Aplikasi Pengelolaan Kerjasama Pembuatan Projek Pada Dinas Komunikasi dan Infromatika Banyumas. Jurnal Teknik Informatika (JUTIF), 1(1), 13-18.

Welda, W., \& Minartiningtyas, B. A. (2017). Sistem Informasi Pengelolaan Kerjasama Bidang Humas pada STMIK STIKOM Indonesia. Jurnal Sisfokom (Sistem Informasi Dan Komputer), 6(2), 86-92. https://doi.org/10.32736/sisfokom.v6i2.252

Yulistina, D., \& Arianti, B. D. D. (2019). E-Katalog Sebagai Sistem Informasi Pemasaran Kopi Sapit Berbasis Web. Edumatic : Jurnal Pendidikan Informatika, 3(2), 45-52. 